\title{
Toll-Like Receptor Signaling
}

\section{Kian-Huat Lim and Louis M. Staudt}

Metabolism Branch, Center for Cancer Research, National Cancer Institute, National Institutes of Health, Bethesda, Maryland 20892

Correspondence: Istaudt@mail.nih.gov

Toll-like receptors (TLRs) are protective immune sentries that sense pathogen-associated molecular patterns (PAMPs) such as unmethylated double-stranded DNA (CpG), single-stranded RNA (ssRNA), lipoproteins, lipo- polysaccharide (LPS), and flagellin. In innate immune myeloid cells, TLRs induce the secretion of inflammatory cytokines (Newton and Dixit 2012), thereby engaging lymphocytes to mount an adaptive, antigen-specific immune

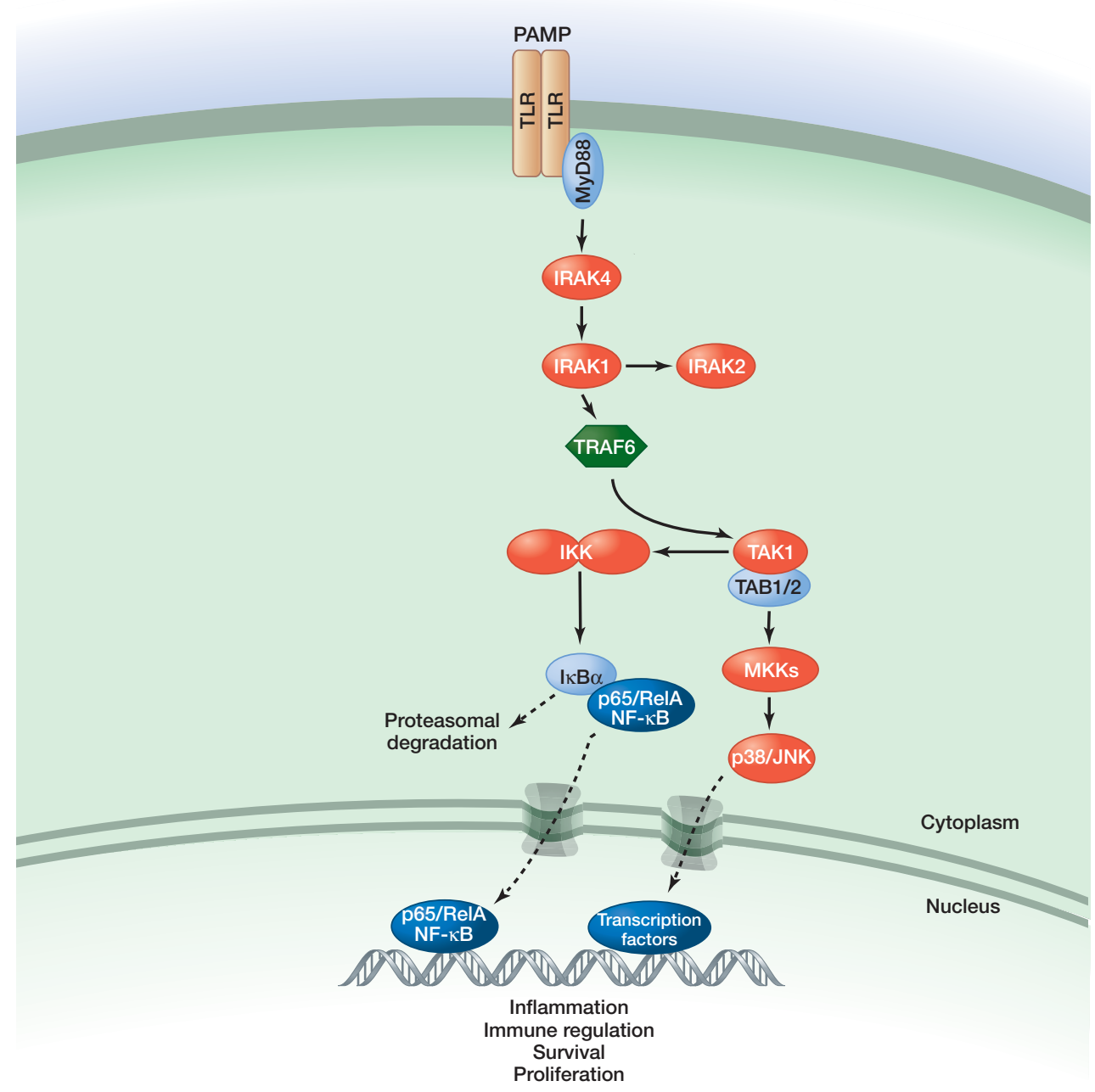

Figure 1. TLR signaling (simplified view). 


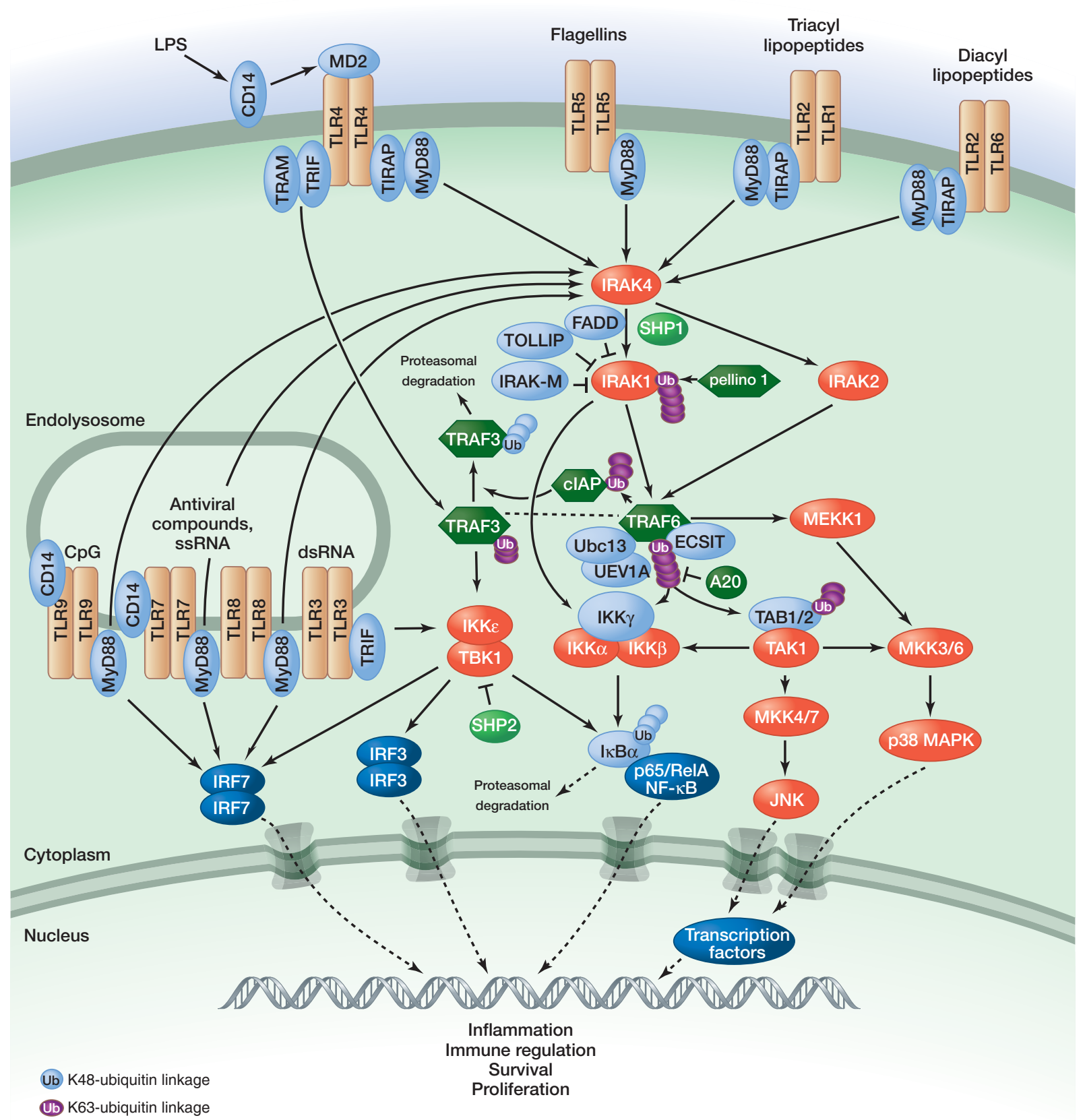

Figure 2. TLR signaling. (Adapted with kind permission of Cell Signaling Technology [http://www.cellsignal.com].)

response (see Fig. 1) that ultimately eradicates the invading microbes (Kawai and Akira 2010).

Identification of TLR innate immune function began with the discovery that Drosophila mutants in the Toll gene are highly susceptible to fungal infection (Lemaitre et al. 1996). This was soon followed by identification of a human Toll homolog, now known as TLR4 (Medzhitov et al. 1997). To date, 10 TLR family members have been identified in humans, and at least 13 are present in mice. All TLRs consist of an amino-terminal domain, characterized by multiple leucine-rich repeats, and a carboxy-terminal TIR domain that interacts with TIR-containing adaptors. $\mathrm{Nu}-$ cleic acid-sensing TLRs (TLR3, TLR7, TLR8, and TLR9) are localized within endosomal compartments, whereas the other TLRs reside at the plasma membrane (Blasius and Beutler 2010; McGettrick and O’Neill 2010). Trafficking of most TLRs from the endoplasmic reticulum (ER) to either the plasma membrane or endolysosomes is orchestrated by 
ER-resident proteins such as UNC93B (for TLR3, TLR7, TLR8, and TLR9) and PRAT4A (for TLR1, TLR2, TLR4, TLR7, and TLR9) (Blasius and Beutler 2010). Once in the endolysosomes, TLR3, TLR7, and TLR9 are subject to stepwise proteolytic cleavage, which is required for ligand binding and signaling (Barton and Kagan 2009). For some TLRs, ligand binding is facilitated by coreceptors, including CD14 and MD2.

Following ligand engagement, the cytoplasmic TIR domains of the TLRs recruit the signaling adaptors MyD88, TIRAP, TRAM, and/or TRIF (see Fig. 2). Depending on the nature of the adaptor that is used, various kinases (IRAK4, IRAK1, IRAK2, TBK1, and IKKe) and ubiquitin ligases (TRAF6 and pellino 1) are recruited and activated, culminating in the engagement of the NF- $\kappa \mathrm{B}$, type I interferon, p38 MAP kinase (MAPK), and JNK MAPK pathways (Kawai and Akira 2010; Morrison 2012). TRAF6 is modified by K63-linked autoubiquitylation, which enables the recruitment of IкB kinase (IKK) through a ubiquitin-binding domain of the IKK $\gamma$ (also known as NEMO) subunit. In addition, a ubiquitin-binding domain of TAB2 recognizes ubiquitylated TRAF6, causing activation of the associated TAK1 kinase, which then phosphorylates the IKK $\beta$ subunit. Pellino 1 can modify IRAK1 with K63-linked ubiquitin, allowing IRAK1 to recruit IKK directly. TLR4 signaling via the TRIF adaptor protein leads to K63-linked polyubiquitylation of TRAF3, thereby promoting the type I interferon response via interferon regulatory factor (IRFs) (Hacker et al. 2011). Alternatively, TLR4 signaling via MyD88 leads to the activation of TRAF6, which modifies cIAP1 or cIAP2 with K63-linked polyubiquitin (Hacker et al. 2011). The cIAPs are thereby activated to modify TRAF3 with K48-linked polyubiquitin, causing its proteasomal degradation. This allows a TRAF6-TAK1 complex to activate the p38 MAPK pathway and promote inflammatory cytokine production (Hacker et al. 2011). TLR signaling is turned off by various negative regulators: IRAK-M and MyD88 short (MyD88s), which antagonize IRAK1 activation; FADD, which antagonizes MyD88 or IRAKs; SHP1 and SHP2, which dephosphorylate IRAK1 and TBK1, respectively; and A20, which deubiquitylates TRAF6 and IKK (Flannery and Bowie 2010; Kawai and Akira 2010).

Deregulation of the TLR signaling cascade causes several human diseases. Patients with inherited deficiencies of MyD88, IRAK4, UNC93B1, or TLR3 are susceptible to recurrent bacterial or viral infections (Casanova et al. 2011). Chronic TLR7 and/or TLR9 activation in autoreactive
B cells, in contrast, underlies systemic autoimmune diseases (Green and Marshak-Rothstein 2011). Furthermore, oncogenic activating mutations of MyD88 occur frequently in the activated B-cell-like subtype of diffuse large B-cell lymphoma and in other B-cell malignancies (Ngo et al. 2011). Inhibitors of various TLRs or their associated kinases are currently being developed for autoimmune or inflammatory diseases and also hold promise for the treatment of B-cell malignancies with oncogenic MyD88 mutations. Many TLR7 and TLR9 agonists are currently in clinical trials as adjuvants to boost host antitumor responses in cancer patients (Hennessy et al. 2010).

\section{REFERENCES}

* Reference is also in this collection.

Barton GM, Kagan JC. 2009. A cell biological view of Toll-like receptor function: Regulation through compartmentalization. Nat Rev Immunol 9: 535-542.

Blasius AL, Beutler B. 2010. Intracellular Toll-like receptors. Immunity 32: $305-315$.

Casanova JL, Abel L, Quintana-Murci L. 2011. Human TLRs and IL-1Rs in host defense: Natural insights from evolutionary, epidemiological, and clinical genetics. Annu Rev Immunol 29: 447-491.

Flannery S, Bowie AG. 2010. The interleukin-1 receptor-associated kinases: Critical regulators of innate immune signalling. Biochem Pharmacol 80: 1981-1991.

Green NM, Marshak-Rothstein A. 2011. Toll-like receptor driven B cell activation in the induction of systemic autoimmunity. Semin Immunol 23: $106-112$.

Hacker H, Tseng PH, Karin M. 2011. Expanding TRAF function: TRAF3 as a tri-faced immune regulator. Nat Rev Immunol 11: 457-468.

Hennessy EJ, Parker AE, O’Neill LA. 2010. Targeting Toll-like receptors: Emerging therapeutics? Nat Rev Drug Discov 9: 293-307.

Kawai T, Akira S. 2010. The role of pattern-recognition receptors in innate immunity: Update on Toll-like receptors. Nat Immunol 11: 373-384.

Lemaitre B, Nicolas E, Michaut L, Reichhart JM, Hoffmann JA. 1996. The dorsoventral regulatory gene cassette spatzle/Toll/cactus controls the potent antifungal response in Drosophila adults. Cell 86: 973-983.

McGettrick AF, O’Neill LA. 2010. Localisation and trafficking of Toll-like receptors: An important mode of regulation. Curr Opin Immunol 22: 20-27.

Medzhitov R, Preston-Hurlburt P, Janeway CA Jr. 1997. A human homologue of the Drosophila Toll protein signals activation of adaptive immunity. Nature 388: 394-397.

* Morrison DK. 2012. MAP kinase pathways. Cold Spring Harb Perspect Biol 4: a011254.

* Newton K, Dixit VM. 2012. Signaling in innate immunity and inflammation. Cold Spring Harb Perspect Biol 4: a006049.

Ngo VN, Young RM, Schmitz R, Jhavar S, Xiao W, Lim KH, Kohlhammer $\mathrm{H}, \mathrm{Xu}$ W, Yang Y, Zhao H, et al. 2011. Oncogenically active MYD88 mutations in human lymphoma. Nature 470: 115-119. 


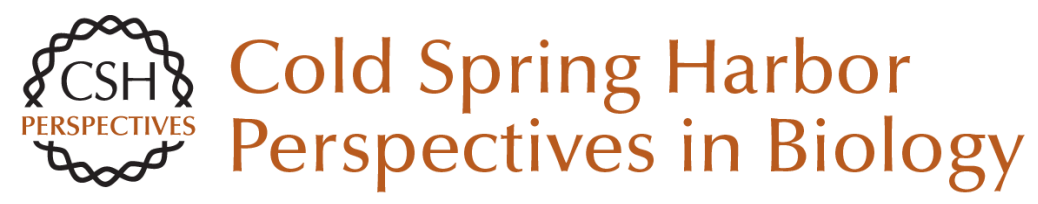

\section{Toll-Like Receptor Signaling}

Kian-Huat Lim and Louis M. Staudt

Cold Spring Harb Perspect Biol 2013; doi: 10.1101/cshperspect.a011247

Subject Collection Signal Transduction

Cell Signaling and Stress Responses Gökhan S. Hotamisligil and Roger J. Davis

Protein Regulation in Signal Transduction Michael J. Lee and Michael B. Yaffe

Synaptic Signaling in Learning and Memory Mary B. Kennedy

Vertebrate Reproduction Sally Kornbluth and Rafael Fissore

Signaling in Lymphocyte Activation Doreen Cantrell

Signaling in Muscle Contraction Ivana Y. Kuo and Barbara E. Ehrlich

Toll-Like Receptor Signaling Kian-Huat Lim and Louis M. Staudt

Signaling Pathways that Regulate Cell Division Nicholas Rhind and Paul Russell
Second Messengers

Alexandra C. Newton, Martin D. Bootman and John D. Scott

Signals and Receptors Carl-Henrik Heldin, Benson Lu, Ron Evans, et al.

Cell Death Signaling Douglas R. Green and Fabien Llambi

Signaling Networks that Regulate Cell Migration Peter Devreotes and Alan Rick Horwitz

Signaling Networks: Information Flow, Computation, and Decision Making Evren U. Azeloglu and Ravi lyengar

Signal Transduction: From the Atomic Age to the Post-Genomic Era Jeremy Thorner, Tony Hunter, Lewis C. Cantley, et al.

Signaling by the TGF $\beta$ Superfamily Jeffrey L. Wrana

Subversion of Cell Signaling by Pathogens Neal M. Alto and Kim Orth

For additional articles in this collection, see http://cshperspectives.cshlp.org/cgi/collection/

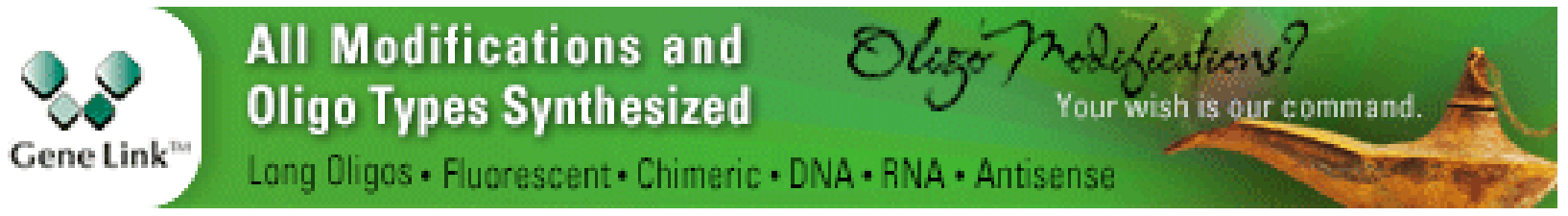

Copyright @ 2013 Cold Spring Harbor Laboratory Press; all rights reserved 